1Secretaria de Estado da Defesa Civil (SEDC) - Rio de Janeiro (RJ), Brasil.

theophilo@globo.com

2 Fundação Oswaldo Cruz (Fiocruz), Escola Nacional de Saúde Pública Sergio Arouca (Ensp) - Rio de Janeiro (RJ), Brasil.

\section{Incident Command System and risk communication: reflections from nuclear emergencies}

\author{
Sistema de Comando de Incidentes e comunicação de risco: reflexões \\ a partir das emergências nucleares
}

Mario Theophilo da Rocha Santos ${ }^{\mathbf{1}}$, Marcos Vinicius de Castro Silva ${ }^{2}$, Telma Abdalla de Oliveira Cardoso ${ }^{2}$

DOI: 10.1590/0103-11042020E207I

\begin{abstract}
Nuclear power plants are designed with systems dedicated to offering a high degree of protection to their workers, the population, and the environment. Between the levels of protection of the population and the environment, there is the nuclear emergency plan. This plan must contain a specific segment related to the management of risk communication to the population. Historically, risk communication techniques have emerged to minimize harm to people, through population panic control strategies. However, this issue is currently underdeveloped in Brazil in the field of nuclear safety. Thus, this work aimed to establish an initial proposal on the use of the theory of Incident Command System as a strategy for managing risk communication in the event of accidents at the Almirante Álvaro Alberto Nuclear Power Plant located in Brazil.
\end{abstract}

KEYWORDS Information management. Organizations for planning and care in disasters. Nuclear emergency control center. Nuclear power plants.

RESUMO Usinas nucleares são projetadas com sistemas dedicados a oferecer um alto grau de proteção aos seus trabalhadores, à população e ao meio ambiente. Entre os níveis de proteção da população e do meio ambiente, encontra-se o plano de emergência nuclear. Este plano deve conter um segmento específico relacionado com o gerenciamento da comunicação de risco à população. Historicamente, técnicas de comunicação de risco surgiram para minimizar danos às pessoas, por meio de estratégias de controle de pânico da população. Entretanto, essa questão atualmente é pouco desenvolvida no Brasil na área de segurança nuclear. Dessa forma, este trabalho visou estabelecer uma proposta inicial no uso da teoria de Sistema de Comando de Incidentes como estratégia de gerenciamento da comunicação de risco em caso de acidentes na Central Nuclear Almirante Álvaro Alberto, localizada no Brasil.

PALAVRAS-CHAVE Gestão da informação. Organizações de planejamento e atendimento a desastres. Centro de controle de emergência nuclear. Centrais nucleares. 


\section{Introduction}

The peaceful use of thermonuclear energy prescribes a series of safety criteria to protect public health, minimizing risks to life and property.

Nuclear power plants are characterized by the use of radioactive materials that produce heat through a nuclear reaction, which is used by a conventional thermodynamic cycle to move an alternator and produce electrical energy. Among the main causes of accidents postulated for a nuclear power plant are coolant loss from the primary system, tube rupture in the heat exchanger, steam line rupture in the secondary system and accidents involving fuel handling. Organizational factors, design deficiencies, degradation of systems due to aging, loss of integrity of containment barriers, inadequate personnel training, equipment failures, operational inexperience, inadequate formulation of procedures, management of waste and external causes are factors that can generate a triggering event ${ }^{1}$. In many cases, accidents occur due to a combination of several factors.

Nuclear accidents are relatively unlikely to occur, however, they produce unpredictable consequences at all levels and, probably, with consequences of international repercussions. That is why there is a strict control carried out by government regulatory bodies, international agencies and organized civil society ${ }^{2}$.

One of the problems observed in the number of victims produced in these types of accidents is the widening of the accident's primary borders, the result of the lack of coordination and management of the quality of communication with the population, the production of false news or half-truths, the manipulation of data and, mainly, the lack of clear guidance in the handling of the uncertainties that emerge from the disaster. All these factors bring the panic that can generate side effects, producing a greater number of victims than the cause of the accident itself ${ }^{3}$.
Thus, this study is aimed at proposing a strategy for improving nuclear emergency response structures in Brazil, in order to contribute to the improvement of nuclear emergency response planning and risk communication management using the Incident Command System theory (ICS).

\section{Historical Retrospective of Nuclear Emergencies from Risk Communication}

During the radiological and nuclear accidents, one of the strategies of biosafety is to protect the population prevention and containment actions that produce shorter exposure times, greater distance from the source and shielding. Thus, evacuating the population away from the accident site (distance) to safe shelters (shielding) quickly (time) is the way conventionally used to protect people. However, there are other factors that can increase the number of victims, such as failures in communication.

Historically, there are examples of problems in the management of risk communication during accidents involving radioisotopes responsible for producing secondary effects with different severities and intensities, such as in the following: Three Mile Island (USA), Goiânia (Brazil), Chernobyl (Ukraine) and Fukushima (Japan). These accidents showed a risk level between 5 and 7, respectively, according to the International Nuclear and Radiological Event Scale (Ines) ${ }^{4}$. This Scale was developed in 1990 by experts, based on the need to communicate the relevance of any event related to the operation of nuclear installations or the conduction of activities that may cause radiation risks to the population. Ines is, therefore, an international event classification scale similar to scales already used in other areas, such as those that compare the severity of earthquakes. Its use can facilitate a common understanding among technicians, the media and the public. 
The events are classified in the scale in seven levels: levels 4-7 are called 'accidents', and levels 1-3 are called 'incidents'. Events with no safety significance are classified as 'Below
Scale' or level 0. Events that have no safety significance regarding radiation or nuclear safety are not rated on the scale. Ines' structure is shown in chart 1 .

Chart 1. Criteria to classify events

\begin{tabular}{|c|c|c|c|}
\hline $\begin{array}{l}\text { Description } \\
\text { Level }\end{array}$ & Health and Environment & Impact on facilities & Defense \\
\hline $\begin{array}{l}\text { Major Accident } \\
\text { Level } 7\end{array}$ & $\begin{array}{l}\text { Major release of radioactive material with } \\
\text { widespread health and environmental } \\
\text { effects requiring the implementation of } \\
\text { planned and extended measures. }\end{array}$ & - & - \\
\hline $\begin{array}{l}\text { Serious ac- } \\
\text { cident } \\
\text { Level } 6\end{array}$ & $\begin{array}{l}\text { Significant release, which requires the } \\
\text { implementation of planned measures. }\end{array}$ & - & - \\
\hline $\begin{array}{l}\text { Accident with } \\
\text { wider conse- } \\
\text { quences } \\
\text { Level } 5\end{array}$ & $\begin{array}{l}\text { Limited release likely to require imple- } \\
\text { mentation of some planned measures. } \\
\text { Several deaths from radiation. }\end{array}$ & $\begin{array}{l}\text { Severe damage to reactor core. Release } \\
\text { of large quantities of radioactive material } \\
\text { within a facility. It may be the result of a } \\
\text { major accident or fire. }\end{array}$ & - \\
\hline $\begin{array}{l}\text { Accident with } \\
\text { local conse- } \\
\text { quences } \\
\text { Level } 4\end{array}$ & $\begin{array}{l}\text { Minor release with unlikely implementa- } \\
\text { tion of planned measures, other than } \\
\text { local controls. At least one death from } \\
\text { radiation. }\end{array}$ & $\begin{array}{l}\text { Fuel melt or damage to fuel, resulting in } \\
\text { more than } 0.1 \% \text { release of core inventory. } \\
\text { Release of significant quantities of radio- } \\
\text { active material within a facility with a high } \\
\text { probability of public exposure. }\end{array}$ & - \\
\hline $\begin{array}{l}\text { Serious incident } \\
\text { Level } 3\end{array}$ & $\begin{array}{l}\text { Exposure greater than ten times the statu- } \\
\text { tory annual limit for workers. Non-lethal } \\
\text { effect on health (e.g., burns). }\end{array}$ & $\begin{array}{l}\text { Severe dispersion with rates greater than } \\
1 \mathrm{~Sv} / \mathrm{h} \text { in an operating area. Acute effects } \\
\text { on a worker's health, with low probability } \\
\text { of public exposure. }\end{array}$ & $\begin{array}{l}\text { Near accident at a nuclear power plant } \\
\text { with no safety provisions remaining. Lost } \\
\text { or stolen highly radioactive sealed source. } \\
\text { Highly radioactive sealed source, without } \\
\text { adequate radiation procedures. }\end{array}$ \\
\hline $\begin{array}{l}\text { Incident } \\
\text { Level } 2\end{array}$ & $\begin{array}{l}\text { Exposure of a member of the public in } \\
\text { excess of } 10 \text { mSv. Exposure of a worker in } \\
\text { excess of the annual statutory legal limits. }\end{array}$ & $\begin{array}{l}\text { Radiation levels of more than } 50 \mathrm{mSv} / \mathrm{h} \text {. } \\
\text { Significant contamination within the } \\
\text { facility. }\end{array}$ & $\begin{array}{l}\text { Significant failures in safety barriers. } \\
\text { Found highly radioactive sealed orphan } \\
\text { source, device or transport, with safety } \\
\text { provisions intact. Inadequate packaging } \\
\text { from a highly radioactive sealed source. }\end{array}$ \\
\hline $\begin{array}{l}\text { Anomaly } \\
\text { Level } 1\end{array}$ & - & - & $\begin{array}{l}\text { Exposure of a person in excess of statu- } \\
\text { tory annual limits. Minor problems with } \\
\text { safety barriers. Low activity lost or stolen } \\
\text { radioactive source, device or transport } \\
\text { package. }\end{array}$ \\
\hline
\end{tabular}

Source: Adapted from IAEA4.

\section{The Three Mile Island Accident}

The most severe nuclear accident occurred near the city of Harrisburg, Pennsylvania, in the United States of America (USA), on March 28, 1979, involving the TMI-2, a nuclear reactor cooled at light pressurized water (model PWR), with 900MW 
generation capacity, at the Three Mile Island Nuclear Power Plant (TMI). The accident was caused by a technical failure of the equipment, followed by a human failure in assessing the condition of the reactor ${ }^{5}$.

The equipment failure caused a gradual loss of coolant water in the reactor core, resulting in partial melting of the fuel element and uranium rods, causing the release of radioactive material out of the core. According to an analysis by the United States Nuclear Regulatory Commission (USNRC) regarding the accident, there were failures in communication between the technicians of the Plant and the authorities of the USNRC headquarters in Washington. The capital received incomplete and inconsistent information and since the first moments, is was clear that decisions should be made on the site of the facility, and not in Washington. A high radiation measurement value inside the plant (12 $\mathrm{rem} / \mathrm{h}$ ) was interpreted in the capital as an environmental dose. This fact caused panic and triggered the evacuation of the population to a $32-\mathrm{km}$ radius around the plant, covering a population of 625,000 people $^{6}$.

The current emergency plan provided for the evacuation of the population within a radius of just $8 \mathrm{~km}$. Thus, traffic accidents, traffic jams and several people were secondary victims due to the lack or mismatch of information 5 .

Sandman 7 reported that, despite the identification of the command unit, there was a lack of definition in the responsibility matrix, a lack of communication among the authorities, other responsible agencies and the public, as well as a team previously prepared for the organization of panic mitigation actions.

The media, being unaware of the information about the effects of radiation and technical terminologies, failed to realize the severity of the situation due to the exaggerated use of technical terms in communication with the press. During the accident, the technical team engaged in resolving the emergency avoided talking to the press, forcing reporters to seek information from unofficial sources ${ }^{8}$. Thus, the news that reached the population came from different areas and from different people, leading to confusion and distrust.

Months after the event, Collins et al. ${ }^{9}$ highlighted persistent health effects on the affected population, such as: increased risk of depression and anxiety and increased symptoms.

\section{Accident at the Chernobyl Nuclear Power Plant}

On April 25, 1986, before a planned interruption of Unit IV of the Chernobyl Nuclear Power Plant in Ukraine, part of the former Soviet Union, operations technicians decided to break with current safety protocols and carry out an experiment designed to test whether the refrigeration of the reactor core would be guaranteed if there was a loss of external energy.

The test aimed to verify if the turbo generator, after the condition of hot shutdown (cut-off of external source and internal power generation by inertia), would provide enough energy to keep the circulating water pumps running, maintaining a safe cooling margin of the reactor, as long as the emergency diesel generators were not put into operation. To carry out this test, operators, authorized by the head of engineering, should gradually reduce the output power of the reactor and within an appropriate time interval to a safer value, according to safety regulations. However, due to the delay in starting the test, the power drop occurred very quickly and close to the value safely allowed. This human error demonstrated a violation of safety rules, resulting in one of the worst nuclear accidents in history $3,10,11$.

In the accident, 237 people were affected, of which 134 were severely exposed or contaminated; there were 32 immediate deaths, as a result of thermal and radiation burns 
among workers, and others who tried to put out the fire. A total of 143 workers and firefighters developed acute radiation syndrome, of which 31 died in 3 months ( 28 died of bone marrow suppression or gastrointestinal damage) ${ }^{\mathbf{1 2}}$.

Twenty years after the accident, in 2006, several United Nations agencies came together to assess the impacts on the main affected countries: Russia, Ukraine and the Republic of Belarus. The study resulting from this meeting showed that, in addition to the deaths and illnesses caused by radiation, the impact on mental health was the greatest public health issue caused by the accident. The lack of information, the amount of rumors and the generated panic produced damages to the affected population, which are still felt nowadays ${ }^{3}$.

Several authors, $7,11,13$ reported the lack of a nuclear emergency response plan. The government, together with the task force, was responsible for managing the consequences of the accident, and there was no formation of an incident communications center. Information was restricted and it took a while for the population to receive it. Rubin ${ }^{\mathbf{1 3}}$ reported that the population received the information when the crisis could no longer be controlled. The first news was announced by a local radio, at the beginning of the evacuation from Pripyat, about 36 hours after the event.

As in the accident at Three Mile Island, in which the information came from different aerial sources, in Chernobyl, these sources were almost entirely from the USA and Western Europe. Sources from the Soviet bloc were rarely heard. The Soviets remained inert about risk communication, encouraging speculation $^{12}$.

\section{Radiological Accident in Goiânia}

In late 1985, a private radiotherapy institute in Goiânia, Brazil, moved to new facilities, and left a Cesium-137 capsule at a radiotherapy unit, without notifying the licensing authority, as required under the license agreement of the institute. Subsequently, the old facilities were partially demolished.

On September 13, 1987, this equipment was tampered with by two people, with the intention of using the containment material to sell it. They removed the radiation head source assembly from the machine, took it home and tried to dismantle it. The radioactive source was in the form of cesium chloride salt, which is highly soluble and readily dispersible. The remains of the source assembly were sold as scrap to the owner of a junkyard. Attracted by the luminescence of the cesium, several people were fascinated, and friends and relatives came to see the phenomenon. Fragments of the source were distributed. The material ended up being scattered in several homes and public places. This occurred for five days, a period when several people had gastrointestinal symptoms resulting from exposure to radiation from the source.

The first symptoms of contamination (nausea, vomiting, dizziness, diarrhea) appeared a few hours after contact with the material. People looked for health services and were diagnosed as victims of some infectious disease. After 15 days of the device dismantling, a local physicist detected the emission of radiation in the sample, which was in the Health Surveillance Coordination of the local Health Department, concluding that the symptoms of those affected were Acute Radiation Syndrome ${ }^{14}$ and alerted the National Nuclear Energy Commission (CNEN). Recognizing the severity of the incident, CNEN requested assistance from the International Atomic Energy Agency (IAEA). The authorities established a screening area for contaminated people at the Olympic stadium, where tents for accommodation were improvised. That night, emergency teams isolated and evacuated several city blocks. Thus, 112,800 people were monitored dosimetrically. Two hundred and nine people with a level of contamination higher 
than normal were identified, 20 were hospitalized, 1 of whom had the right forearm amputated, and 4 died. After the death of the first 2 victims, pathologists at the reference hospital in the city refused to perform necropsies due to the risk of contamination and exposure ${ }^{15}$.

Brazilian authorities did not release official statements or other information to the public while carrying out the response operations. Rumors spread throughout the city, prompting some reporters and the public to go to the Olympic stadium in search of information. This lack of information gave wings to the imagination and fostered the fear of the unknown, causing panic among health and security agents and the population, who, at all costs, wanted to leave the regions close to the accident without planning. Despite the rumors and the growing social unrest, government officials have not established communication mechanisms to answer questions and inform the public.

The clothing of the radiology technicians of the federal government agency, in charge of monitoring people and the environment, as well as their equipment, produced fear in people. Facial masks hindered the understanding of what the professionals were saying. The approach was cold and there were no one to establish a dialog between the technical area and the population.

It is noteworthy that Brazil had a structure to deal with radiological or nuclear emergencies. At the time of the accident, this structure was formed by: 1) emergency plan for accidents occurred in nuclear installations (Central Nuclear Almirante Álvaro Alberto - CNAAA, located in Angra dos Reis); and 2) response plan to deal with non-nuclear installations; which, in the perception of those responsible for the elaboration, could be associated with minor accidents, such as transport accidents or radiography facilities ${ }^{\mathbf{1 4}}$. However, Goiânia was not adapted to this structure. Nevertheless, the CNEN emergency coordinator used the experience of the radiological accident that occurred in 1983 in the city of Juarez, Mexico, and had similar characteristics. Although there was no predefined chain of command for this situation, there was an emergency plan ${ }^{\mathbf{1 4}}$.

Only in the weeks after the accident did the authorities in Goiânia develop a public communication program, in an attempt to correct misinformation and restore public confidence. They distributed 250,000 copies of a leaflet, advising on radioactivity and radiation, in an effort to limit misinformation. They also established a telephone number to answer questions or receive information about possible contamination ${ }^{15}$. However, the city was besieged by prejudices from society outside of that local reality ${ }^{\mathbf{1 4}}$. The social damage lasted for a long time for the population, who did not get any support from the authorities, because they were not prepared to respond to an accident of that nature. The psychological consequences of the accident, as in Chernobyl ${ }^{3}$, were much more comprehensive than the contamination by Cesium-137 itself. Consequently, the population suffers psychological and psychosomatic problems until the present day ${ }^{16,17}$.

\section{Fukushima Nuclear Accident}

The accident at the Fukushima Nuclear Power Station, which occurred on March 11, 2011, was considered a nuclear disaster, caused by the melting of the core of three of the plant's six nuclear reactors. The failure occurred when the plant was hit by a tsunami secondary to an 8.9 magnitude earthquake on the Richter scale. Due to the collapse of an energy tower, there was an interruption of electricity supply to the station, causing the reactors not to cool down with water. Even when deactivated, they heated up, leading to a partial fusion of the core in reactors I, II and III. The fact was aggravated by the formation of hydrogen gas, causing an explosion that destroyed the upper concrete lining of the housing buildings of reactors I, III and 
IV. In reactor II, the explosion caused the core to be exposed. Several fires started in the reactor IV. Thus, important amounts of radioactive material were released into the environment, notably iodine and cesium, contaminating the air, soil and water ${ }^{\mathbf{1 8}}$.

After 30 hours from the start of the disaster, Japanese Prime Minister Kan Naoto addressed the population about the earthquake and tsunami that hit Tokyo and the northern half of Japan's main island. However, the minister himself was not aware of the severity of the ongoing accident ${ }^{18}$. The Tokyo electric power company (TEPCO), which operated the Fukushima Nuclear Power Plant, supervised by the Japanese regulatory body called Japan's Nuclear and Industrial Safety Agency (Nisa), had not informed the government about what was happening. Only five days after the disaster began, the Prime Minister, after visiting the Nuclear Power Plant, became aware of the severity of the facts. In view of this situation, the population that has been exposed to the risks for five days was concerned exclusively with the tsunami and the earthquake. After the observation, the minister addressed the Japanese people, warning about the risks of contamination and radiation exposure, as well as for new radiation leaks at the nuclear power plant. On that occasion, the minister opted to extend the exclusion radius of 20 kilometers, which was previously mentioned in the planning, to a $30-\mathrm{km}$ radius from the Fukushima plant, recommending everyone to stay indoors. Only after taking this action, the authorities began to show the population and the rest of the world the severe situation in Fukushima ${ }^{19}$.

Six days after the accident, several countries criticized information management in Japan. The IAEA, to which Japan is affiliated, has publicly protested against the impropriety of the Japanese action. Radiation measurements within a 50-kilometer radius from the nuclear power plant site in northern Japan showed high levels of cesium. It was forbidden to sell food in that area. The government recommended that tap water should not be used to prepare food. Levels of plutonium contamination were detected in the soil at two sites at the nuclear power plant.

Kortov and Ustyantsev ${ }^{\mathbf{2 0}}$ compared the consequences of the accidents in Chernobyl and Fukushima (table 1). This table shows the main differences between the two accidents.

Table 1. Consequences of accidents at the Chernobyl and Fukushima nuclear power plants

\begin{tabular}{lrr}
\hline Accident & Chernobyl & Fukushima \\
\hline Amount of radioactive substances released into the atmosphere & $5.2 .10^{\mathbf{1 8}} \mathrm{Bq}$ & $6.3 .10 \mathbf{1 7} \mathrm{Bq}$ \\
Territorial contamination & $450,000 \mathrm{~km}^{2}$ & $8,000 \mathrm{~km}^{2}$ \\
Contamination of the territory of other countries & $\begin{array}{l}250,000 \mathrm{~km}^{2} \mathrm{in} \\
\text { Western Europe }\end{array}$ & $0 \mathrm{~km}^{2}(\mathrm{a})$ \\
Evacuation Area & $10,800 \mathrm{~km}^{2}$ & $1,100 \mathrm{~km}^{2}$ \\
Number of evacuees & 400,000 people & 83,000 people \\
Acute radiation mortality within 4 months after the accident & 28 & 0 \\
\hline Source: Kortov and Ustyantsev20 (15). & & \\
(a) The accident in Fukushima did not cause pollution in other countries. & &
\end{tabular}


The population, despite its resilient culture, became suspicious of the information given by the authorities, which were disconnected and generated unease. Through the press, the population received news and rumors spread due to the increase in radiation rate measures. About 15,884 victims died because of the tsunami and earthquake, 300,000 were evacuated; and of these, 1,600 deaths were related to evacuation conditions ${ }^{\mathbf{1 8}}$.

Although Japan produced mechanisms for handling disasters, given the unique characteristics of the event, the initial stage of responses was faced with circumstances that differed from the anticipated scenarios and were operated in an unforeseen manner. Therefore, capacities were not fully used, which resulted in the inadequacy of these responses ${ }^{\mathbf{2 1}}$.

It should be noted that, in Japan, there is a decentralization of responsibilities in crisis management, including those related to nuclear security. In fact, there is no unified system for executing command and control functions. Thus, from what was established in the legal instruments, the Prime Minister was in charge, even though he did not play a role in integrating the instances in crisis management. In addition, the safety council, which should be called upon to deliberate on crisis management measures, was not summoned to respond to the accident because the nuclear disaster was not considered within the safety council's mandate. On the other hand, in the political framework, there was no structure that could serve as a command for incidents in place of the security council. Consequently, government decision-making was conducted through ambiguous procedures ${ }^{22}$.

\section{Risk Communication}

The risk communication theory emerged to improve the way of informing about the risks to which people are exposed. This theory was motivated mainly by the growth of accidents in industrial plants ${ }^{23}$. Thus, through their control agencies, governments began to demand that the emergency plans for industrial plants have a specific chapter directed to risk management and communication.

Risk communication provides the population with information about a specific condition of a disaster or even about transitions in behavioral states of the evolution of the situation that threatens health, safety or the environment. It is an interactive process of exchanging information about risks (nature, severity and acceptability) among individuals, institutions and communities. Awareness depends on information, so risk communication is the basis for preparing responses to accidents and emergencies. Communication at the time of emergency helps the population to understand and adopt protective behaviors. It allows authorities and specialists to listen to the population and respond to their concerns and needs, so that the advice is relevant, reliable and acceptable 24 .

In a radiological or nuclear emergency, communication is one of the decisive components for meeting the objectives of the response ${ }^{8}$. Even in non-emergency situations, those who can act as first responders, such as the police, health care providers or civil defense, spend a lot of time in their daily lives responding to requests for information instead of initiating dialogs with their team members or warning the public about the risk $\mathbf{7 , 8}$.

Communication must contain clear and concise messages, with a vocabulary that does not differ from the understanding of the receiver with less intellectual training. Changes in the class of warnings, in the evolution of the emergency, must be managed in a gradual and cautious way, allowing the recipients of the message to be able to process it and react according to the expected and previously trained protocol25.

Risk communication protocols must be planned, periodically reviewed and trained with the society that is the target of their construction. The planned actions of risk communication must depart from models that reproduce 
the simple information generated by specialists. They must include the dimensions of public perception in the risk analysis and the interaction of the segments involved, bringing greater adherence to the planned actions ${ }^{\mathbf{2 6}}$.

The segments involved in risk communication must have criteria of trust and credibility for their robustness. These values are built in an insidious and progressive way, using coherence and consistency of actions, competence and ethics. One value that can affect the propagated truth is the scientific uncertainty contained in the information package provided to the population. We cannot guarantee information that is subject to uncertainty. This must be addressed in the composition of the communication strategy, in order not to produce friable statements over time. This type of communication failure can lead to loss of credibility and control of communication effectiveness ${ }^{25}$.

\section{Current Accident Response Organization at the Almirante Álvaro Alberto Nuclear Power Plant}

CNAAA, located in the city of Angra dos Reis, in the state of Rio de Janeiro, has an emergency plan with a set of protocols and procedures necessary to respond to a nuclear accident. Among them, the initial triggering protocol is foreseen for the fulfillment of the measures established by the Brazilian Nuclear Program Protection System (Sipron), responsible for ensuring integrated planning, establishing structures that, when notified about an event that could trigger nuclear accident, must act immediately in the assembly of response management structures, composed of three emergency coordination and control centers (national, state, local), as well as an information management center dedicated to the press and the population ${ }^{27,28}$.

\section{The National Center for the Management of Nuclear Emergency Situation (CNAGEN)}

Headquartered in Brasília, its role is to advise the federal government on the evolution of the nuclear emergency, as well as supervise and coordinate the support of federal agencies, national and international public and private entities, the supplementary actions undertaken and the means used in response to a nuclear emergency situation.

\section{State Center for Nuclear Emergency Management (Cestgen)}

Located in the General Department of Civil Defense, in the city of Rio de Janeiro, it is responsible for advising the decisions of the state government in the event of emergency situations, in addition to coordinating the support of public and private agencies based in its area of influence, complementing the actions taken and the means used to respond to the nuclear emergency.

\section{Center for Coordination and Control of Nuclear Emergency (CCCEN)}

Located in Angra dos Reis (RJ), it is responsible for coordinating the actions of the various agencies based in the municipality and surroundings, managing the emergency locally, as well as promoting support for actions and strategies for the propagation of information and control of rumors in the event of an emergency.

\section{Center for Information in Nuclear Emergency (Cien)}

Headquartered in Angra dos Reis, it is responsible for managing risk communication, monitoring rumors, as well as for disseminating information to the public and the press.

Cien is composed of one representative from each of the following institutions: 
Municipal Civil Defense, State Civil Defense, Eletronuclear and CNEN. Even though the parity provides a significant representation of those responsible for panic control in the emergency, the structure is not internally organized, being composed of a leader and other subordinates.

\section{Use of the Incident Command System in Risk Communication Management}

The ICS was developed in 1970, in response to forest fires in southwest California' ${ }^{29}$. To fight fire, different US agencies had to act together, and the daily evaluation of operations showed the lack of a clear command structure, difficulties in establishing priorities and converging objectives, lack of common terminology and lack of integration and standardization in communications. The ICS emerged as an integration tool between agencies $^{29}$.

It focuses on decision-making about response actions. It is a standardized incident management strategy in the scene, with all the risks, which allows for the adoption of an integrated organizational structure to meet the complexities and demands of single or multiple incidents, regardless of jurisdictional barriers. The size of this structure must be measured according to the needs of response to the type of emergency or disaster; however, it has considerable internal flexibility and can grow or decrease to meet different needs. This flexibility makes management more economical and efficient for small and large situations. Thus, teams with any combination of resources, either unique or from different classes, can be aggregated to meet a command and control process ${ }^{30}$.

In the ICS, in order not to have loss of control in operational actions, each professional involved in the incident does not report to many people. Thus, leaders have a limit of five to seven people under their supervision. Another important point is the integrity of communications, that is, there is a single communication plan between all agencies, using the same terminology, channels and interconnected frequencies.

In the communication protocol, the extent of the data networks will depend on the size and complexity of the incident. The plan contains the operational and administrative conditions that define who, with whom, in what way, when and how it will be implemented. This detail avoids transmission congestion, which creates problems in the development of incident response ${ }^{31}$.

In the ICS command network, the roles coordinated by the Incident Commander (IC) and the security, public information, liaison and intelligence advisers are integrated. In addition, it provides for the existence of sections of operations, logistics, planning and administration/finance, for the coordination of specific tasks aimed at handling the incident and managing risk information and communication ${ }^{32}$ (figure 1). 
Figure 1. Command network of the Incident Command System (ICS)

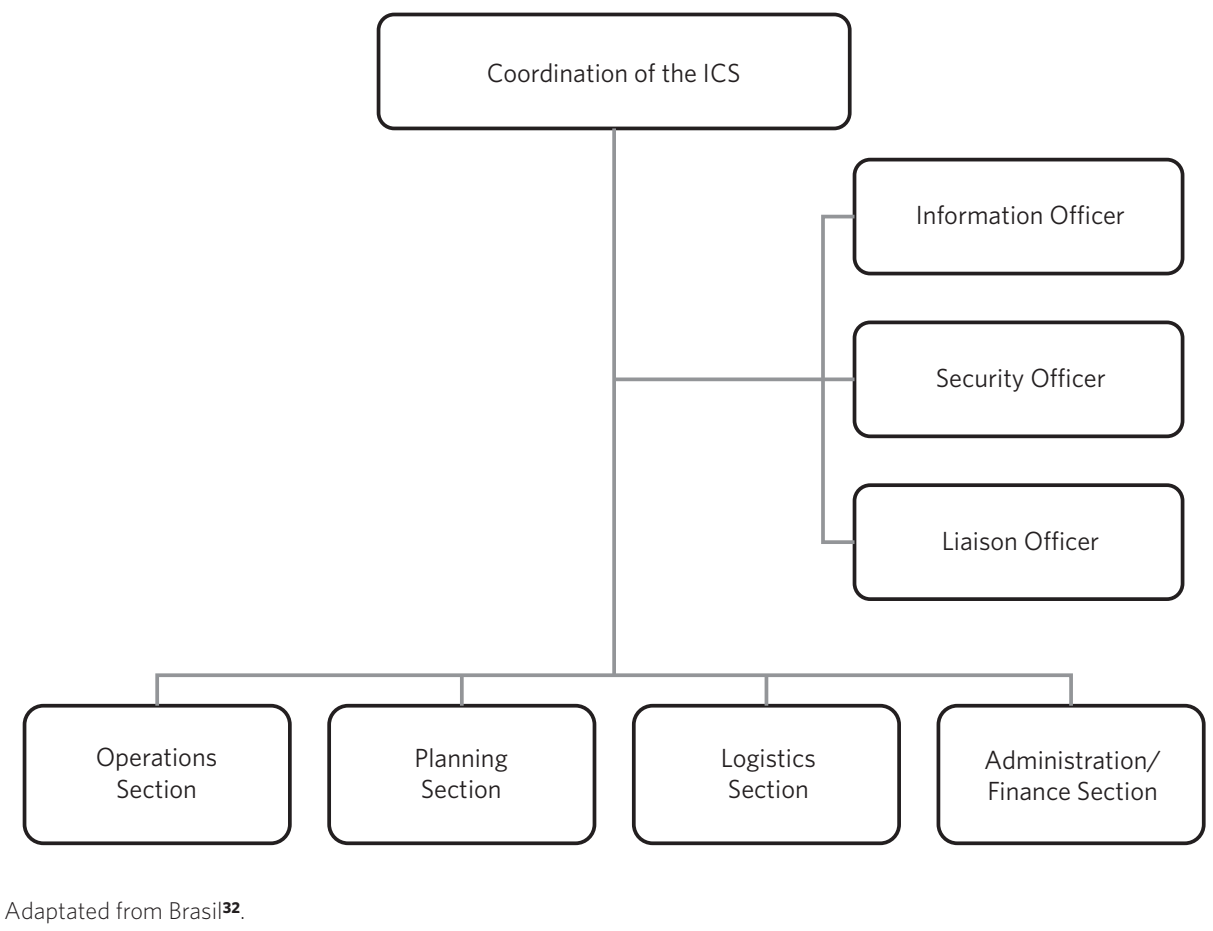

\section{Coordination}

The coordinator defines the objectives and priorities of the incident and has overall responsibility for the event, as well as for the safety of Cien. The coordinator is responsible for information management and risk communication to be made available to the Public Information Officer (PIO). The CI is also responsible for establishing and maintaining contact with all agencies participating in the incident.

Initially, the allocation of tactical resources and the supervision of operations will be under the coordinator's direct supervision. The coordinator has a team composed of secretaries who assist in the preparation and registration of meetings and other direct advisory activities.

The coordinator has a sub-coordinator, who has the same qualifications. Bothe can work together and the sub-coordinator can replace the coordinator when necessary.

\section{Public Information Officer}

The PIO is the public information advisor, who is in charge of disseminating information to the population, organizations and authorities, including the media, who seek information about the incident.

The PIO seeks to obtain data on the event, its location, the time it begins, cause, existence of victims, immediate measures taken and actions established to control the situation. The PIO is in charge of preparing a report on the operating situation, difficulties and threats to Cien, and these data must be reported periodically to the coordinator, who will establish the foundations for the planning and execution of information management. This information helps to guide the population and the media in the use of official information in their reports, reducing the risk of rumors and controlling panic ${ }^{33}$. Thus, it is important that the PIO is objective, 
simple and concise, using a language with a minimum of technical terms, so as not to cause noise in communication; stick to the facts and not make inferences, enhancing message understanding and propagation ${ }^{\mathbf{3 4}}$.

Although the PIO concentrates all the governance of the incident information, advising the coordinator, there is a communication team that supports information retrieval, processing, elaboration and provision, in its different stages.

\section{Security Officer}

The security officer is responsible for conducting risk analyses and implementing mitigation measures. The Security Officer assesses and monitors the security conditions of the site, inspects and develops actions to guarantee the safety of the personnel involved.

In addition, the security officer advises the $\mathrm{CI}$ on issues related to the security of the incident and works in line with the Operations Section to ensure security as much as possible, given the circumstances, including the use of appropriate protective equipment and the implementation of safer tactical options.

Cien is a sensitive place, where safety information is disseminated orally, in writing, and through the information highway. Thus, specific spaces should be allocated to media representatives, different from the one in which the information is developed.

The Center is also the target of groups that do not understand the work developed there, being a space liable to actions information theft, uprising or conflict. Security Officers must foresee such situations using intelligence and physical security. Therefore, they must establish accreditation systems, access control, as well as security agents and systems.

\section{Liaison Officer}

The liaison officer establishes liaison between the Cien coordinator and the PIO. The liaison officer is the primary contact between the representatives of the supporting bodies involved and the coordinator. This officer provides a summary of information (briefing) to the representatives, solving doubts and any concerns about the operation. In addition, the liaison officer filters access, without losing the quality of the agent's demand.

\section{Operations Section}

It is responsible for the development and implementation of strategies and actions necessary to achieve the objectives established in the communications plan. This means organizing, assigning and monitoring all tactical field resources assigned to an incident, including air operations. Therefore, most incident resources are assigned to the Operations Section.

It must be directed by a professional with technical and tactical knowledge to deal with the problem in question.

The section should be organized into segments, divided into branches of information: written press, television, radio, internet, rumors control, intelligence, data concatenation, production of public information and production of information for government authorities.

\section{Planning Section}

The Planning Section is responsible for information and intelligence collection, analysis and dissemination. In addition, it projects data related to communication and risk management. This section works closely with the CI to make sure that information is shared effectively and results in an efficient planning process to meet the needs of the commander and operations. This includes assessing current information, predicting future events, preparing alternative strategies to be selected by the coordinator, keeping the status of resources up to date, documenting activities, responding to a plan for progressive 
demobilization, to be carried out when the team is no longer needed for the operation.

This section is directed by a chief and is formed by the areas of resources, situation, documentation and demobilization, and may also employ technical specialists to satisfy any specific tactical-strategic need. It is also responsible for assessing the situation and prognosis, to define the need for personnel and materials.

\section{Logistics Section}

It is responsible for supporting the tactical risk management and communication plan. It is composed of the resource and service support branches, supporting the incident response activities. Its role is to request all the necessary material and personnel, distribution, storage and registration of the resources used, establishing facilities for resting, food and maintenance, and promoting services, such as: supply, repair and transportation; establishment of a communication and support system for the health unit and for the members of the Cien work teams.

The Logistics Section and the Administration and Finance Section must work together to hire goods and services necessary to support the incident.

Initially, the logistics is concentrated in a single person; however, with the development of the incident, subunits must be added to the initial structure, thus establishing the branches of support and services. These branches are supervised by the head of logistics.

The supporting branch consists of the supply unit and the facility unit. The supply unit is responsible for ordering, storing, processing and providing all resources related to risk management and communication, such as tactical, supporting resources (including personnel) and consumables. The facility unit is responsible for building, maintaining and demobilizing the facilities used to support operations, as well as for the security service. This unit establishes the environment of the crisis room, communications and all other facilities (networks, equipment of different types of media, living room, press room, dorms and toilets), preferably taking advantage of existing structures. It may be necessary to install another unit to support operations: such as transport, for vehicle control.

The service branch is responsible for the communication, food and health units. The activities of the communication units are the development of plans for the most effective and efficient use and testing of communication equipment, distribution and registration of equipment, network communicability and frequency of use. The food unit is responsible for the establishment of kitchen facilities, food ordering, menu, preparation and distribution of meals, as well as food preservation. It must plan and anticipate needs, both in number of meals and in the most appropriate place of distribution; for this reason, it works in conjunction with the Planning Section, as well as with the facility unit. On the other hand, the health unit is responsible for the development of procedures and routines to assist health events that occurred in Cien, transport and assistance planning for patients, in addition to controlling the processing of records and documentation related to accidents and diseases.

\section{Administration and Finance Section}

It is established to manage financial services, accounting for the cost analysis of an incident. This includes contract negotiation and monitoring, time tracking of resources, such as personnel and equipment; control of documentation, processing and compensation for accidents or material damage that occurred during the incident.

It has a direct relationship with the Logistics Section, to guarantee the hiring and/or acquisition of all the resources necessary to manage the incident. 
This Section can establish units according to the extent and severity of the incident, the number of agencies involved, and the financial need generated. These are units of time, acquisition and cost.

The time unit shall ensure that the daily record of staff service time is being prepared in accordance with the requirements of the respective bodies. If possible, activity time will be collected after each operational period. The leader of the time unit can count on assistants who are related to the time counting policy of the different agencies involved. The records must be checked, and the exceeding hours must be declared in a separate record.

The acquisition unit is responsible for the operation of all financial matters related to purchases and contracts. It articulates with local suppliers, prepares and signs contracts.

The cost unit is responsible for the promotion and cost assessment of the incident, ensuring the registration of all resources. With this data, it prepares a cost analysis, including estimates of costs in the event of an extension of operation activities.

\section{Final considerations}

The modeling proposed in this study for Cien, related to the Almirante Álvaro Alberto Nuclear Power Plant, works with the hypothesis that it is possible to introduce a unified command model in information management, in which the coordinator of the Information Center institutes the existing divisions in the ICS to manage process governance.

The ICS is a proven management system, based on successful practices, the result of decades of lessons learned in the organization and management of emergencies and incidents.

Considering that nuclear accidents are very unlikely to occur, the intended method for the validation of this model would be carried out based on nuclear emergency exercises, which are currently carried out systematically at the Nuclear Complex of Angra dos Reis, in the state of Rio de Janeiro.

The existing data memory of emergency exercises from previous years would be the database for measuring the improvement of the response system and the performance indicators to be used.

To face the challenges, the model needs to be essentially interdisciplinary, as it integrates several agencies, organizations and institutions around a common management structure, ensuring that the operational team can meet the tactical objectives by providing logistical and administrative support to the operational area and the efficient use of available resources, avoiding redoubling efforts.

The inherent flexibility of the tool means that it can expand or contract to meet the different needs imposed by the event being attended. Thus, among the results expected in the proposed model, there is the possibility of its use, both from the point of view of operational cost and efficiency of the management approach, in any situation, either complex or simple, regardless of its type or magnitude, whether routine or planned, such as conferences, concerts and major matches, or in major incidents such as disasters, industrial chemical accidents, disease outbreaks and acts of terrorism.

\section{Collaborators}

Santos MTR (0000-0003-0801-9067)*, Silva MVC (0000-0001-7461-0109)* and Cardoso TAO (0000-0002-5430-7273)* also contributed to the design, data collection, preparation of the draft and writing, critical review of the content and approval of the final version of the manuscript 


\section{References}

1. Ha-Duong M, Journé V. Calculating nuclear accident probabilities from empirical frequencies. Env. Syst. Decisions. 2014; 34(2):249-58.

2. International Atomic Energy Agency. IAEA TECDOC $\mathrm{n}^{\circ}$ 955. Generic assessment procedures for determining protective actions during a reactor accident [internet]. Vienna: IAEA; 1997. [acesso em 2019 mar 10]. Disponível em: https://www-pub.iaea.org/MTCD/ publications/PDF/te_955_prn.pdf.

3. Baverstock K, Williams D. O acidente de Chernobyl 20 anos depois: avaliação das consequências e resposta internacional. Ciênc. Saúde Colet. 2007; 12(3):68998.

4. International Atomic Energy Agency. The International Nuclear and Radiological Event Scale. User's Manual. Viena: IAEA; 2013.

5. Walker JM. Three Mile Island. A Nuclear Crisis in Historical Perspective. Berkeley: University of California; 2004.

6. US Nuclear Regulatory Commission. Lessons learned from the Three Mile Island-Unit 2. Advisory Panel. NUREG/CR-6252 [internet]. Washington: NRC; 1994. [acesso em 2019 mar 8]. Disponível em: https:// tmi2kml.inl.gov/Documents/2c-L2-NUREG/NUREGCR-6252,\%20Lessons\%20Learned\%20from\%20 the\%20TMI-2\%20Advisory\%20Panel\%20(1994-08). pdf.

7. Sandman PM. Tell it like it is. IAEA Bulletin. 2006; 47(2):9-14.

8. Becker MT. Emergency communication and information issues in terrorist events involving radioactive materials. Biosecur Bioterror. 2004; 2(3):195-203.

9. Collins DL, Baum A, Singer JE. Coping with chronic stress at Three Mile Island: psychological and biochemical evidence. Health Psyc. 1983; 2(2):149-66.
10. Tronea M, Ciurea C. Nuclear safety culture attributes and lessons to be learned from past accidents. Intern Nuclear Safety J. 2014; 3(3):1-7.

11. International Atomic Energy Agency. INSAG-7. The Chernobyl Accident: updating of INSAG-1. A report by the international nuclear safety advisory group. Safety Series n0 75-INSAG-7 [internet]. Vienna: IAEA; 1992. [acesso em 2019 fev 27]. Disponível em: https:// www-pub.iaea.org/MTCD/publications/PDF/Pub913e_web.pdf.

12. Tuttle RM, Becker DV. The Chernobyl accident and its consequences: update at the millennium. Semin Nucl Med. 2000; 30(2):133-40.

13. Rubin DM. How the News media reported on Three Mile Island and Chernobyl. J Communication. 1987; $37(3): 42-57$.

14. International Atomic Energy Agency. Radiological accident in Goiania [internet]. Vienna: IAEA; 1988. [acesso em 2019 fev 27]. Disponível em: https://www-pub.iaea.org/MTCD/publications/PDF/Pub815_web. pdf.

15. Curado MP. The communication of radiological risk to populations exposed to a radiological accident: considerations concerning the accident in Goiânia. Radiat Prot Dosim. 1996; 68(3-4):283-6.

16. Helou S, Costa Neto SB. Césio-137: história do acidente e atuação da psicologia. In: Helou S, editor. Césio-137: consequências psicossociais do acidente de Goiânia. 2. ed. Goiância: UFG; 2014. p. 13-29.

17. Palestino CSF, Dias FP. Aspectos sociais dos vinte anos desde o acidente radiológico com césio-137. In: Helou S. editor. Césio-137: consequências psicossociais do acidente de Goiânia. 2. ed. Goiânia: UFG; 2014. p. 120-33.

18. Lipscy P, Kushida K, Incerti T. The Fukushima disaster and Japan's nuclear plant vulnerability in comparative 
perspective. Environ Sci Technol. 2013; 47(12):60828.

19. Ohnishi T. The disaster at Japan's Fukushima-Daiichi nuclear power plant after the March 11, 2011 earthquake and tsunami, and the resulting spread of radioisotope contamination. Radiat Res. 2012; 177(1):1-14.

20. Kortov V, Ustyantsev Y. Chernobyl accident: Causes, consequences and problems of radiation measurements. Radiat Meas. 2013; (55):12-6.

21. Imanaka T, Hayashi G, Endo S. Comparison of the accident process, radioactivity release and ground contamination between Chernobyl and Fukushima-1. J Radiat Res. 2015; 56(suppl1):i56-61.

22. Saskawa Peace Foundation. The Fukushima nuclear accident and crisis management. Lessons for Japan-US alliance cooperation. Tokyo: SPF; 2012.

23. De Marchi B. The Sevezo Directive: an Italian pilot study in enabling communication. Risk Anal. 1991; 11(2):207-15.

24. Aakko E. Risk communication, risk perception and public health. WMJ. 2004; 103(1):25-7.

25. Fisher A. Risk Communication Challenges. Risk Anal. 1991; 11(2):173-9.

26. Bradbury JA. The policy implications of differing concepts of risk. Sci Technol Hum Values. 1989; 14(4):380-99.

27. Brasil. Secretaria de Assuntos Estratégicos. Portaria $\mathrm{n}^{\circ}$ 27, de 27 de março de 1997. Aprova a norma geral que dispõe sobre a instalação e o funcionamento dos centros encarregados da resposta a uma situação de emergência nuclear. Diário Oficial da União. 31 Mar 1997.

28. Brasil. Lei ${ }^{\circ} 12.731$, de 21 de novembro de 2012. Institui o Sistema de Proteção ao Programa Nuclear Brasileiro - SIPRON e revoga o Decreto Lei no 1.809, de 7 de outubro de 1980. Diário Oficial da União. 22 Nov 2012.

29. Federal Emergency Management Agency. ICS-0200.c Basic incident command system for initial response, ICS 200. Washington, DC: FEMA; 2019.

30. Federal Emergency Management Agency. Incident Management Handbook: B-761 Interim. Washington, DC: FEMA; 2010.

31. International Fire Service Trainning Association. Essentials of Fire Fighting and Fire Department Operations. 6. ed. Stillwater: Fire Protection Publications; 2013.

32. Brasil. Ministério da Integração Nacional. Secretaria Nacional de Defesa Civil. Sistema de Comando em Operações. Florianópolis: UFSC; 2010.

33. Deal T, Bettencourt M, Deal V, et al. Beyond Initial Response: using the National Incident Management System's Incident Command System. 2. ed. Bloomington: Author House; 2012.

34. Spiegelhalter D. Risk and Uncertainty Communication. Annu. Rev Stat. Appl. 2017; 4(1):31-60.

Received on 08/29/2019

Approved on: 02/29/2020

Conflict of interests: non-existent

Financial support: non-existent 